\title{
Long-term outcome after combined kyphoplasty and intraoperative radiotherapy (Kypho-IORT) for vertebral tumors
}

Frederic Bludau ${ }^{1 \dagger}$, Laura Winter ${ }^{1 \dagger}$, Grit Welzel², Udo Obertacke1, Frank Schneider², Frederik Wenz ${ }^{3}$, Arne Mathias Ruder ${ }^{2 *+}$ and Frank A. Giordano $2,4+$

\begin{abstract}
Introduction: The spine represents the site which is most frequently affected by bone metastases in patients with systemic cancer. Of all local treatment options, combined kyphoplasty and intraoperative radiotherapy (Kypho-IORT) provides both, instantaneous stabilization and immediate pain relief. We here report on the long-term outcomes of the largest cohort treated with Kypho-IORT to date.

Methods: Between 2009 and 2019 a total of 104 patients underwent Kypho-IORT to vertebral tumors in the thoracic, lumbar, or sacral spine with transpedicular kyphoplasty and intraoperative irradiation with a needle-shaped electronic brachytherapy source at our center. Patients were treated either on trial, within the prospective Kypho-IORT studies (NCT01280032 and NCT02773966), or, after completion of the study, off trial but compliant with the study protocol. Follow-up and imaging with computed tomography (CT) or magnetic resonance imaging was scheduled after 3 and 6 months and then bi-annually.

Results: A total of 143 vertebrae (89 thoracic spine, 53 lumbar spine, and 1 sacral spine) were treated in 104 patients. The median follow-up was 14.5 months (range 0.4-109). Local progression occurred in 10 patients (10 vertebrae) after a median time of 22.3 months (range 1.5-73) resulting in local control rates of 97.1, 95.9, and $94.2 \%$ at 6,12 , and 24 months, respectively. Overall survival was $74.6,61.7$, and $50.3 \%$ at 6,12 , and 24 months, respectively. A single serious adverse event was reported.
\end{abstract}

Conclusion: In addition to immediate pain reduction and stabilization, Kypho-IORT shows excellent long-term local control with minimal side effects.

Keywords: Kypho-IORT, Electronic brachytherapy, Intraoperative radiotherapy, Kyphoplasty, Spine, Vertebral metastases

*Correspondence: arne.ruder@umm.de

${ }^{\dagger}$ Frederic Bludau, Laura Winter, Arne Mathias Ruder, and Frank A. Giordano have contributed equally to this work and share the first authorship or the last authorship

${ }^{2}$ Department of Radiation Oncology, University Medical Center Mannheim, Mannheim Medical Faculty, Heidelberg University, Mannheim, Germany

Full list of author information is available at the end of the article

\section{Introduction}

The spine is the most common site for the occurrence of bone metastases [1]. Additionally, intraosseous hemangiomas frequently occur as benign tumors of the spine [2]. Treatment should focus on palliation of pain, stabilization and local tumor control with therapeutic options including radiation therapy, surgical intervention or radiofrequency ablation [3-5]. Due to continuous advancements in systemic cancer therapy, any delay or pause of systemic treatment caused by local interventions should original author(s) and the source, provide a link to the Creative Commons licence, and indicate if changes were made. The images or other third party material in this article are included in the article's Creative Commons licence, unless indicated otherwise in a credit line to the material. If material is not included in the article's Creative Commons licence and your intended use is not permitted by statutory regulation or exceeds the permitted use, you will need to obtain permission directly from the copyright holder. To view a copy of this licence, visit http://creativecommons.org/licenses/by/4.0/. The Creative Commons Public Domain Dedication waiver (http://creativeco mmons.org/publicdomain/zero/1.0/) applies to the data made available in this article, unless otherwise stated in a credit line to the data. 
be avoided. With the advent of advanced therapies, life expectancy of cancer patients continues to rise and local control as well as quality of life gain further importance [6-8].

Kypho-IORT consists of cement augmentation kyphoplasty and intraoperative irradiation as a "one-stop-shop" intervention for the treatment of tumors in vertebral bodies of the thoracic, lumbar, and sacral spine. In a recent dose escalation and cohort expansion phase I/II trial with a total of 61 patients we showed a significant median pain reduction at the first postoperative day and a subsequent sustained pain reduction. The 3-, 6-, and 12-month local progression free survival (L-PFS without considering death as an endpoint) was $97.5,93.8$, and 93.8\% [9]. To further investigate this combined approach, a multicentric randomized phase III trial (NCT02773966) was designed to test Kypho-IORT against external beam radiotherapy (EBRT) as standard-of-care for painful vertebral metastases [10]. We here report our long-term experience of 10 years with patients treated at our institution as the largest single-center cohort analysis to date.

\section{Methods}

All prospective and retrospective data acquisition and analysis was approved by the local institutional review board. All patients treated with Kypho-IORT between 2009 and 2019 at our institution were included in this analysis, whereas treatment was either carried out on trial within the prospective Kypho-IORT studies (NCT01280032 and NCT02773966) or, after completion and closure of the phase I/II study or before the start of the phase III study, off trial but fully compliant with the study protocol. Patients with up to three painful and/ or unstable metastases of pathologically confirmed cancer or benign tumors (hemangioma) in vertebral bodies (Tomita 1/2) of the thoracic, lumbar, and/or sacral spine were eligible for treatment. In brief, following a bipedicular approach and placement of guidance sleeves, a 50-kV X-ray source (Intrabeam, Carl Zeiss Meditec AG, Oberkochen, Germany) equipped with a needle applicator (diameter $4.2 \mathrm{~mm}$ ) was inserted into the vertebral metastasis. A dose of 8 Gy was then prescribed to a distance of 8,11 , or $13 \mathrm{~mm}$ from the isocenter in the tip of the source. Following irradiation, transpedicular kyphoplasty with cement augmentation was performed [9]. Thereafter, patients continued with standard-of-care systemic therapy, depending on their primary cancer.

Baseline imaging was performed (computed tomography, $\mathrm{CT}$, or magnetic resonance imaging, MRI) within 7 days after surgery. Follow-up spinal imaging was scheduled every 6 months, or in case new symptoms occurred (e. g. increased pain or neurological deficits).
Median follow-up was defined by the time between Kypho-IORT and the last follow-up. Local recurrence was defined as tumor recurrence within a treated vertebra. Survival was measured as time frame from the intervention until death by any cause.

Local control rate (LC per treated vertebra) and overall survival rate (OS per patient) at $6,12,24,36,48$, and 60 months were estimated using the Kaplan-Meier method. All statistical analyses were performed using SPSS (V. 24.0; IBM, Armonk, NY).

\section{Results}

A total of 104 patients were included in this analysis. The median age at the time of Kypho-IORT was 62 years (range $32-85$ years). $56 \%$ of the patients were female and $48 \%$ were male. A total of 143 lesions were treated, with 89 lesions located in the thoracic spine, 53 in the lumbar spine, and 1 in the sacral spine. Of these, 23 treatments were performed as 2-level interventions, and 8 as 3-level interventions. All vertebral bodies were intraoperatively irradiated with $8 \mathrm{~Gy}$, which were prescribed to a distance from the isocenter of 8,11 , or $13 \mathrm{~mm}$ in 48,20 , and 75 vertebrae, accounting for 33.6, 14.0 , and $52.4 \%$ of the vertebrae treated, respectively. The median follow-up was 14.5 months (range 0.4109). We detected 10 local recurrences with 7 located in the thoracic spine and 3 located in the lumbar spine. Dose prescription distance to the recurrent lesions was 8,11 , and $13 \mathrm{~mm}$ in 2,3 , and 5 lesions, accounting for $4.2,15$, and $6.7 \%$ of recurrences in the 8,11 , and $13 \mathrm{~mm}$ subgroup, respectively. In one patient, a locally recurrent tumor in a pre-fractured vertebra caused a vertebral compression fracture (VCF). Median time to recurrence was 22.3 months (range 1.5-73). The underlying diseases of patients with local recurrence were breast (4), prostate (2), colorectal (1), renal (1) and lung cancer (1) or soft tissue sarcoma (1). The LC at 6, 12, $24,36,48$, and 60 months for the thoracic spine was 97.2, 95.1, 95.1, 80.1, 80.1, and 80.1\%, and for the lumbar spine 97.1, 97.1, 93.4, 93.4, 83.0, and 83.0\%, respectively, with no recurrence in the sacral spine resulting in a combined LC of 97.1, 95.9, 94.2, 85.5, 81.8, and 81.8\% (Fig. 1). No difference was detected for LC between the thoracic and the lumbar spine (log-rank test, $p=0.663$ ). A total of 66 patients died, resulting in an OS at 6,12 , $24,36,48$, and 60 months of $74.6,61.7,50.3,39.0,37.7$, and $25.2 \%$ (Fig. 2). None of the mortalities were related to the procedure. A single serious adverse event (SAE) of temporary painful nerve root irritation immediately after surgery was noted. No adjacent level vertebral fractures occurred. Detailed data is reported in Table 1. 

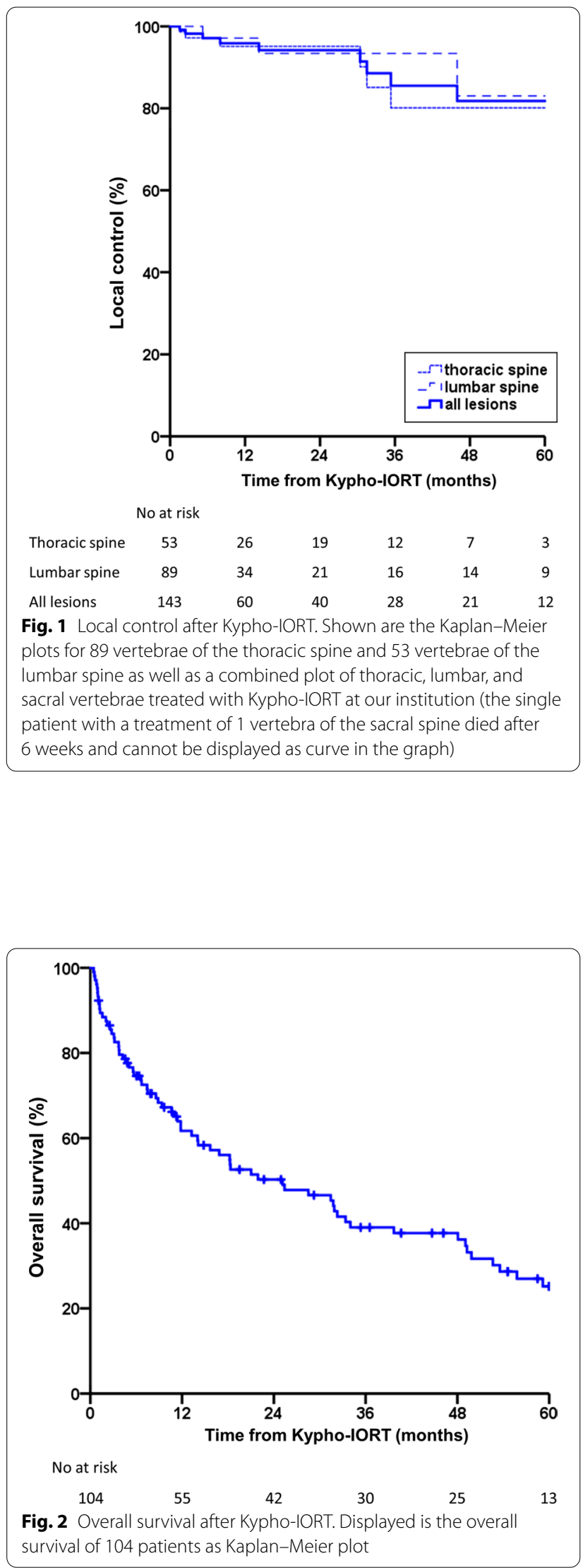

\section{Discussion}

We here report the results for the largest cohort of patients treated with Kypho-IORT to date. The findings for LC for 6 months are in line with earlier results from a smaller cohort with shorter follow-up treated within the phase I/II trial at our institution [9]. The overall excellent control rates after Kypho-IORT compare favorably with data from external beam radiotherapy (EBRT) or stereotactic body radiotherapy (SBRT) [11, 12]. With increasing life expectancy due to improved systemic therapy (including targeted therapies and immunomodulators) and promising therapy options even for patients with metastatic cancer [13], both long-term efficacy and toxicities of local therapies for spinal metastases are gaining further importance.

EBRT, the most widespread standard, offers moderate pain reduction but with the drawback of a delayed onset within several weeks after irradiation, while pain relief in Kypho-IORT is immediate [9, 11]. SBRT to spinal lesions frequently results in flare-up of pain (20$70 \%$ ) before pain relief but shows higher local control rates than those achieved with EBRT [12, 14-16]. However, a major complication after SBRT is vertebral compression fracture (VCF), which may occur in up to $40 \%$ of patients, specifically in case of pre-existing sintering [17-19]. Albeit occurrence or progression of VCF after SBRT resulted in a low mean increase of pain, SBRT may further pose a risk of VCF in adjacent vertebrae $[17,20]$. The inherent stabilization and restoration of the vertebral body by cement augmentation virtually eradicates the risk of VCF or further progression of VCF, especially for patients with pre-existing VCF which would have a high probability of progredient VCF after SBRT. Adjacent level fractures after kyphoplasty in patients with (oligo-)metastatic cancer seem to be less likely to occur - in contrast to osteoporotic patients - due to the rather normal bone structure in the vicinity of the treated vertebra which is not affected by the procedure [21]. Since radiation from electronic brachytherapy as part of Kypho-IORT is not only confined to the vertebral body but also of low energy (50 kV X-rays), it can be performed in any operating room suitable for c-arm fluoroscopy [22]. Combining kyphoplasty with radiofrequency ablation instead in regard of radioprotection is therefore not necessary and yielded inferior results in local control [5]. Previous findings showed that kyphoplasty with irradiation can be accomplished in an average time of $65 \mathrm{~min}$ and, due to its percutaneous approach, is a surgical intervention, but is considered minimally invasive $[9,23]$. Systemic therapy can thus be concomitantly administered without aggravating side-effects (e. g. prolonged wound healing time or increased radiation toxicity). 
Table 1 Details of the cohort. Listed are the entities with the number of patients as well as vertebrae treated and the local recurrences per entity

\begin{tabular}{lccc}
\hline Entities & Patients/proportion & Vertebrae/proportion & $\begin{array}{c}\text { Local recurrences } \\
\text { (vertebrae)/ } \\
\text { proportion }\end{array}$ \\
\hline Breast cancer & & & $4 / 40 \%$ \\
Prostate cancer & $46 / 44.2 \%$ & $70 / 49.0 \%$ & $2 / 20 \%$ \\
Lung cancer & $16 / 15.4 \%$ & $20 / 14.0 \%$ & $1 / 10 \%$ \\
Gastrointestinal cancer & $15 / 14.4 \%$ & $21 / 14,7 \%$ & $1 / 10 \%$ \\
Multiple myeloma & $10 / 9.6 \%$ & $11 / 7.7 \%$ & 0 \\
Renal cancer & $3 / 2.9 \%$ & $5 / 3.5 \%$ & $1 / 10 \%$ \\
Melanoma & $3 / 2.9 \%$ & $4 / 2.8 \%$ & 0 \\
Sarcoma & $3 / 2.9 \%$ & $4 / 2.8 \%$ & $1 / 10 \%$ \\
Other gynecological cancers & $3 / 2.9 \%$ & $3 / 2.1 \%$ & 0 \\
Other urogenital cancers & $3 / 2.9 \%$ & $3 / 2.1 \%$ & 0 \\
Others (haemangioma) & $1 / 1.0 \%$ & $1 / 1.4 \%$ & 0 \\
\hline
\end{tabular}

The limitations of our study, specifically when measuring $\mathrm{LC}$, are the retrospective nature and the heterogeneous histologies and stages (e. g. oligometastatic vs. advanced systemic disease) with patients receiving various other therapies after Kypho-IORT [24].

One could argue that the high LC is - at least partlyaided by systemic therapies since more than half (63\%) of the lesions treated in our cohort arose from breast or prostate cancers, where anti-hormonal therapy, antiresorptive agents, targeted therapies or chemotherapy can effectively contribute to local control at the site of Kypho-IORT [25]. However, also more than half of the recurrent tumors still stemmed from breast (4 patients) or prostate cancer ( 2 patients) while only 4 patients with recurrent tumors suffered from cancers that are classically less susceptible to systemic therapies (lung, renal, or colorectal cancer, and soft tissue sarcoma) thus suggesting a high innate efficacy of Kypho-IORT independent of histology.

In conclusion, Kypho-IORT resembles a "one-stopshop" procedure that offers fast pain relief, instant stabilization, and exceptional long-term local tumor control for patients with vertebral metastases.

\section{Acknowledgements}

We thank all patients and their families for their participation in this trial. The support of Matthias Benker shall be gratefully acknowledged.

\section{Authors' contributions}

$\mathrm{FB}, \mathrm{UO}, \mathrm{FW}$, and FG designed the underlying trials. FB, UO, FS, FW, AMR and FG performed the treatments. FB and LW obtained the follow-up data. FB, GW, AMR, and FG analyzed and interpreted the patient dataset. FB, AMR and FG were the major contributors in writing the manuscript. FB, LW, AMR, and FG contributed equally to this work and share the first authorship or the last authorship. All authors read and approved the final manuscript.

\section{Funding}

Open Access funding enabled and organized by Projekt DEAL. The sponsor of this trial was the Mannheim Medical Faculty, Heidelberg University, and it was conducted with institutional funds.

Availability of data and materials

The datasets used and analyzed during the current study are available from the corresponding author on reasonable request.

\section{Ethics approval and consent to participate}

The underlying trials (NCT01280032 and NCT02773966) were approved by the institutional review board, Ethikkommission II, Mannheim Medical Faculty, Heidelberg University. All patients gave their written consent before participation.

\section{Consent for publication}

Not applicable.

\section{Competing interests}

LW, GW, UO, FW and AMR have no competing interests to disclose. FB and FS report grants and personal fees from Carl Zeiss Meditec AG, during the conduct of the study; FG reports grants, personal fees, and patents from or related to Carl Zeiss Meditec AG, grants from Elekta AB; grants and personal fees from NOXXON Pharma AG, personal fees from Bristol-Myers Squibb, personal fees from Roche Pharma AG, personal fees from MSD Sharp and Dohme GmbH, personal fees from AstraZeneca $\mathrm{GmbH}$, non-financial support from Oncare $\mathrm{GmbH}$, outside the submitted work.

\section{Author details}

${ }^{1}$ Department of Orthopedic Surgery and Trauma Surgery, University Medical Center Mannheim, Mannheim Medical Faculty, Heidelberg University, Mannheim, Germany. ${ }^{2}$ Department of Radiation Oncology, University Medical Center Mannheim, Mannheim Medical Faculty, Heidelberg University, Mannheim, Germany. ${ }^{3}$ University Medical Center Freiburg, Freiburg University, Freiburg, Germany. ${ }^{4}$ Department of Radiation Oncology, University Hospital Bonn, University of Bonn, Bonn, Germany.

Received: 24 August 2020 Accepted: 6 November 2020

Published online: 12 November 2020 


\section{References}

1. Perrin RG, Laxton AW. Metastatic spine disease: epidemiology, pathophysiology, and evaluation of patients. Neurosurg Clin N Am. 2004;15(4):365-73.

2. Huvos AG. Bone tumors: diagnosis, treatment and prognosis. 2nd ed. New York: W.B. Saunders Company and Cbs Educational and Professional Publishing; 1987.

3. Lutz S, Balboni T, Jones J, Lo S, Petit J, Rich SE, et al. Palliative radiation therapy for bone metastases: update of an ASTRO evidence-based guideline. Pract Radiat Oncol. 2017;7(1):4-12.

4. Berenson J, Pflugmacher R, Jarzem P, Zonder J, Schechtman K, Tillman $J B$, et al. Balloon kyphoplasty versus non-surgical fracture management for treatment of painful vertebral body compression fractures in patients with cancer: a multicentre, randomised controlled trial. Lancet Oncol. 2011;12(3):225-35.

5. Prezzano KM, Prasad D, Hermann GM, Belal AN, Alberico RA. Radiofrequency ablation and radiation therapy improve local control in spinal metastases compared to radiofrequency ablation alone. Am J Hosp Palliat Care. 2019;36(5):417-22.

6. Khalil DN, Smith EL, Brentjens RJ, Wolchok JD. The future of cancer treatment: immunomodulation, CARs and combination immunotherapy. Nat Rev Clin Oncol. 2016;13(5):273-90.

7. Botta L, Dal Maso L, Guzzinati S, Panato C, Gatta G, Trama A, et al. Changes in life expectancy for cancer patients over time since diagnosis. J Adv Res. 2019;20:153-9.

8. Kokkonen K, Tasmuth T, Lehto JT, Kautiainen H, Elme A, Jääskeläinen A-S, et al. Cancer patients' symptom burden and health-related quality of life (HRQoL) at tertiary cancer center from 2006 to 2013: a cross-sectional study. Anticancer Res. 2019;39(1):271-7.

9. Bludau F, Welzel G, Reis T, Schneider F, Sperk E, Neumaier C, et al. Phase I/ II trial of combined kyphoplasty and intraoperative radiotherapy in spinal metastases. Spine J. 2018;18(5):776-81.

10. Bludau F, Welzel G, Reis T, Abo-Madyan Y, Sperk E, Schneider F, et al. Combined kyphoplasty and intraoperative radiotherapy (Kypho-IORT) versus external beam radiotherapy (EBRT) for painful vertebral metastases-a randomized phase III study. BMC Cancer. 2019;19(1):430.

11. Koswig S, Budach V. Remineralisation und Schmerzlinderung von Knochenmetastasen nach unterschiedlich fraktionierter Strahlentherapie (10mal 3 Gy vs. 1 mal 8 Gy)Eine prospektive Studie. Strahlenther Onkol. 1999;175(10):500-8.

12. Husain ZA, Sahgal A, De Salles A, Funaro M, Glover J, Hayashi M, et al. Stereotactic body radiotherapy for de novo spinal metastases: systematic review. J Neurosurg Spine. 2017;27(3):295-302.

13. Palma DA, Olson R, Harrow S, Gaede S, Louie AV, Haasbeek C, et al. Stereotactic ablative radiotherapy versus standard of care palliative treatment in patients with oligometastatic cancers (SABR-COMET): a randomised, phase 2, open-label trial. Lancet. 2019;393(10185):2051-8.

14. Chang U-K, Cho W-I, Kim M-S, Cho CK, Lee DH, Rhee CH. Local tumor control after retreatment of spinal metastasis using stereotactic body radiotherapy; comparison with initial treatment group. Acta Oncol. 2012;51(5):589-95.

15. Balagamwala EH, Naik M, Reddy CA, Angelov L, Suh JH, Djemil T, et al. Pain flare after stereotactic radiosurgery for spine metastases. J Radiosurg SBRT. 2018;5(2):99-105.

16. Chiang A, Zeng L, Zhang L, Lochray F, Korol R, Loblaw A, et al. Pain flare is a common adverse event in steroid-naïve patients after spine stereotactic body radiation therapy: a prospective clinical trial. Int J Radiat Oncol Biol Phys. 2013;86(4):638-42.

17. Mantel F, Sweeney RA, Klement RJ, Hawkins MA, Belderbos J, Ahmed M, et al. Risk factors for vertebral compression fracture after spine stereotactic body radiation therapy: long-term results of a prospective phase 2 study. Radiother Oncol. 2019;141:62-6.

18. Rose PS, Laufer I, Boland PJ, Hanover A, Bilsky MH, Yamada J, et al. Risk of fracture after single fraction image-guided intensity-modulated radiation therapy to spinal metastases. J Clin Oncol. 2009:27(30):5075-9.

19. Moussazadeh N, Lis E, Katsoulakis E, Kahn S, Svoboda M, DiStefano NM, et al. Five-year outcomes of high-dose single-fraction spinal stereotactic radiosurgery. Int J Radiat Oncol Biol Phys. 2015;93(2):361-7.

20. Lockney DT, Hopkins B, Lockney NA, Coleman CZ, Rubin E, Lis E, et al. Adjacent level fracture incidence in single fraction high dose spinal radiosurgery. Ann Transl Med. 2019;7(10):211.

21. Pflugmacher R, Schroeder RJ, Klostermann CK. Incidence of adjacent vertebral fractures in patients treated with balloon kyphoplasty: two years' prospective follow-up. Acta Radiol (Stockholm, Sweden: 1987). 2006;47(8):830-40.

22. Schneider F, Clausen S, Jahnke A, Steil V, Bludau F, Sutterlin M, et al. Radiation protection for an intraoperative $X$-ray source compared to C-arm fluoroscopy. Z Med Phys. 2014;24(3):243-51.

23. Barzilai O, McLaughlin L, Amato M-K, Reiner AS, Ogilvie SQ, Lis E, et al. Minimal access surgery for spinal metastases: prospective evaluation of a treatment algorithm using patient-reported outcomes. World Neurosurg. 2018;120:e889-901.

24. Barzilai O, Versteeg AL, Sahgal A, Rhines LD, Bilsky MH, Sciubba DM, et al. Survival, local control, and health-related quality of life in patients with oligometastatic and polymetastatic spinal tumors: a multicenter, international study. Cancer. 2019;125(5):770-8.

25. Saad F, Gleason DM, Murray R, Tchekmedyian S, Venner P, Lacombe L, et al. A randomized, placebo-controlled trial of zoledronic acid in patients with hormone-refractory metastatic prostate carcinoma. J Natl Cancer Inst. 2002;94(19):1458-68.

\section{Publisher's Note}

Springer Nature remains neutral with regard to jurisdictional claims in published maps and institutional affiliations.
Ready to submit your research? Choose BMC and benefit from:

- fast, convenient online submission

- thorough peer review by experienced researchers in your field

- rapid publication on acceptance

- support for research data, including large and complex data types

- gold Open Access which fosters wider collaboration and increased citations

- maximum visibility for your research: over 100M website views per year

At BMC, research is always in progress.

Learn more biomedcentral.com/submissions 